\title{
Application of Zn/Al layered double hydroxides for the removal of nano- scale plastic debris from aqueous systems
}

\author{
Ekta Tiwari ${ }^{\mathrm{a}}$, Nisha Singh ${ }^{\mathrm{a}}$, Nitin Khandelwal ${ }^{\mathrm{a}}$, Fazel Abdolahpur Monikh ${ }^{\mathrm{c}}$, \\ Gopala Krishna Darbha ${ }^{a, b, *}$
}

${ }^{a}$ Environmental Nanoscience Laboratory, Department of Earth Sciences, Indian Institute of Science Education and Research (IISER) Kolkata, Mohanpur, 741246, West Bengal, India

${ }^{\mathrm{b}}$ Centre for Climate and Environmental Studies, Indian Institute of Science Education and Research (IISER) Kolkata, Mohanpur, 741246, West Bengal, India

${ }^{\mathrm{c}}$ Institute of Environmental Sciences (CML), Leiden University, P.O. Box 9518, 2300 RA Leiden, Netherlands

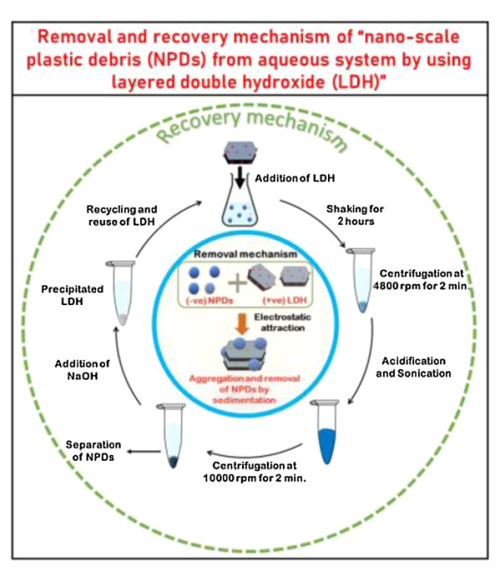

A R T I C L E I N F O

\section{Editor: L. Eder}

Keywords:

Nano-scale

Plastic

Adsorption

Wastewater

Removal

Nanoplastics

\begin{abstract}
A B S T R A C T
Nano-scale plastic debris (NPDs) are emerging as potential contaminants as they can be easily ingested by aquatic organisms and carry many pollutants in the environment. This study is aimed to remove NPDs from aqueous environment for the first time by using eco-friendly adsorption techniques. Initially, the interaction between NPDs and synthesized $\mathrm{Zn}-\mathrm{Al}$ layered double hydroxide (LDH) was confirmed by $\mathrm{pH}$ titration of $\mathrm{Zn}-\mathrm{Al}$ LDH against NPDs at varying mass ratio (50:1 to 50:7) and FTIR analysis for both before and after $2 \mathrm{~h}$ of contact time. Fast removal was observed in deionized water and synthetic freshwater with maximum sorption capacity $\left(\mathrm{Q}_{\max }\right)$ of $164.49 \mathrm{mg} / \mathrm{g}, 162.62 \mathrm{mg} / \mathrm{g}$, respectively, according to Sips isotherm. Whereas, removal was least in synthetic hard water having a $\mathrm{Q}_{\max }$ value of $53 \mathrm{mg} / \mathrm{g}$. For $2 \mathrm{mM}$ concentration of $\mathrm{SO}_{4}{ }^{2-}$ and $\mathrm{PO}_{4}{ }^{3-}$, the adsorption capacity significantly decreased to $2 \%$. The removal efficiency was found $100 \%$ at $\mathrm{pH} 4$, while at $\mathrm{pH} 9$,
\end{abstract}

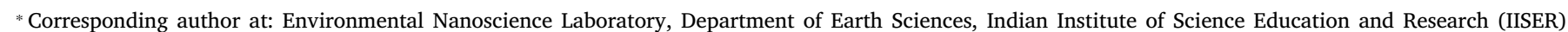
Kolkata, Mohanpur, 741246, West Bengal, India.

E-mail addresses: gkdarbha@gmail.com,gkdarbha80@yahoo.com (G.K. Darbha). 
it reached $37 \%$ due to increased competitive binding and destabilization of LDH under alkaline conditions. The process of sorption was spontaneous in different types of water studied. The study reveals that $\mathrm{Zn}-\mathrm{Al} \mathrm{LDH}$ can be used as potential adsorbent for the removal of NPDs from freshwater systems.

\section{Introduction}

Pollution caused by the exponential use of plastic items in our daily life is contributing to the accumulation of wreckage in aquatic ecosystems and a matter of serious concern all across the world (Tallec et al., 2019; Nguyen et al., 2019; Lehner et al., 2019; Besseling et al., 2014). An enormous amount of plastic debris released from the household, industrial, and agricultural wastes are the primary source of plastic pollution (Alimi et al., 2018). Once they reach the environment, its physical and chemical weathering leads to the generation of the microscale $(<5 \mathrm{~mm})$ and nanoscale plastic debris (NPDs) $(<1 \mu \mathrm{m})$ in the environment (Koelmans et al., 2015). Direct release of microplastics and NPDs in the environment from personal care, cosmetics, and thermal cutting of polystyrene also has been reported (Hernandez et al., 2017; Zhang et al., 2012). Wastewater treatment plants (WWTPs) are considered as the main source for the release of micron-sized plastic particles in the freshwater system. For example, Mason et al. reported a discharge of $\sim 50,000$ up to nearly 15 million micron-sized plastic particles from the wastewater treatment plant (Mason et al., 2016).

Once these microplastic and NPDs enter the aquatic environment, their interaction differs with aquatic organisms and other components of the environment as compared to their pristine form. This difference can be attributed due to the change in their chemical structure and physical properties (Yu et al., 2019a). The cleavage of the bonds present on the surface of polymers makes them more vulnerable to degradation (Lehner et al., 2019). Weathered forms of microplastic, as well as NPDs, were found to have toxic effects on aquatic organisms. However, NPDs are of particular concern because of their smaller size and high surface area to volume ratio. Due to their small size, they can easily penetrate the biological barriers as compared to their microplastic counterparts (Lehner et al., 2019; Booth et al., 2016; Bhattacharya et al., 2010; Rothen-Rutishauser et al., 2007; Gopinath et al., 2019). Further, it has been widely reported that the availability and toxicity of NPDs to aquatic organisms depend on their stability in the environment. Various stability and aggregation studies of NPDs under varying environmental conditions had been found that ionic strength, dissolved organic matter, and suspended solids play an important role in controlling their fate in the aquatic environment (Singh et al., 2019; Yu et al., 2019b; Liu et al., 2019). Due to increased bioavailability, these particles subsequently get transferred from one trophic level to others via the food chain (Cedervall et al., 2012; Mattsson et al., 2015; Chae et al., 2018). Recent studies documented the uptake, accumulation, and toxicity of polystyrene NPDs in mussels, zooplankton, algae, and daphnia (Wegner et al., 2012; Pitt et al., 2018; Nolte et al., 2017; Nasser and Lynch, 2016). However, an increased generation of NPDs may have a possible detrimental effect on human health being at the top of the food chain (Revel et al., 2018).

The toxicity induced by individual NPDs in aquatic organisms could be marginal and may not have any chronic effects. Nevertheless, the synergistic toxic effects of other contaminants in the presence of NPDs are well studied (Lee et al., 2019; Ma et al., 2016). Several studies have shown that the hydrophobic surface of NPDs has a high tendency to adsorb persistent organic pollutants (POPs) like polycyclic aromatic hydrocarbons (PAHs) and polychlorinated biphenyls (PCBs) and thereby increasing its toxicity towards various organisms (Zhang et al., 2018; Jeong et al., 2018). It has been found that they are also involved in the association and transport of heavy metals in the environment (Alimi et al., 2018; Yu et al., 2019a; Darbha et al., 2012).

Different techniques such as membrane bioreactor, coagulation, and ultrafiltration were used at WWTPs for the removal of microplastics (Talvitie et al., 2017; Lares et al., 2018; Arossa et al., 2019; Ma et al., 2019; Long et al., 2019). However, the removal efficiency is still poor. Moreover, the mentioned techniques are expensive and have limitations in the removal of nano-sized particles. Therefore, this underlines an urgent need to find a possible solution for the removal of NPDs from the aqueous environment.

Limited work on the removal of microplastics and no reported studies on the removal of NPDs from aqueous solutions allowed us to form the major applied scientific objective. The focus of the current work is to explore the adsorption as an eco-friendly and cost-effective technique for the removal of NPDs from aqueous systems. Based on the preliminary experiments on the interaction between layered double hydroxides (LDH) and NPDs, batch sorption studies were carried out. $\mathrm{LDH}$, which is also called anionic clay, has been used with or without

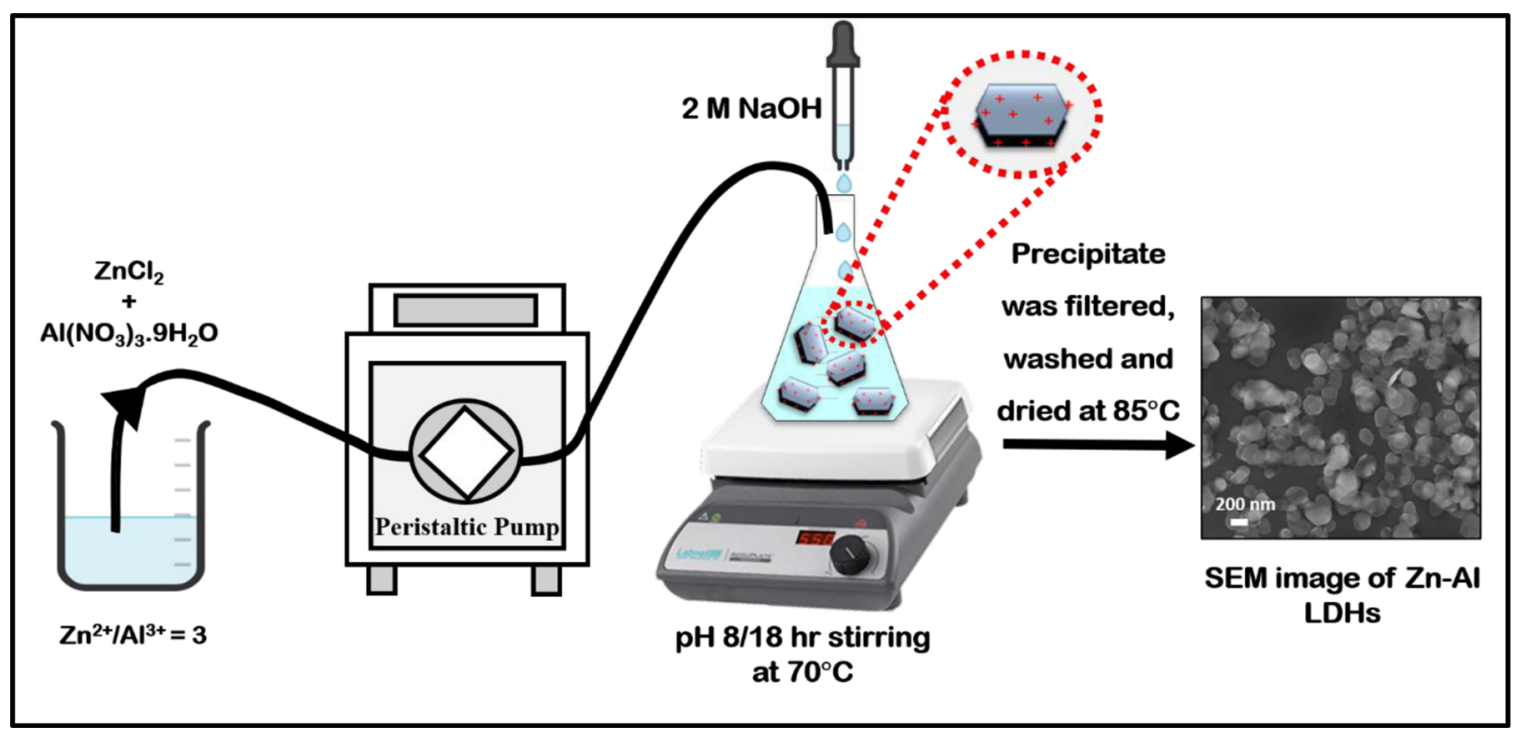

Fig. 1. Schematic of Zn-Al LDH synthesis by co-precipitation method. 
modification for the removal of heavy metals and organic contaminants such as $\mathrm{Cr}$, $\mathrm{Cu}$, dyes, pesticides, etc. (Lazaridis et al., 2004; Li et al., 2016; Cardoso and Valim, 2006; Chaara et al., 2011). LDH can be considered as the most appropriate adsorbent for the anionic contaminants without any modification as they have high anion exchange capacity ( $\mathrm{AEC} \approx 3 \mathrm{meq}^{-1}$ ) (Legrouri et al., 2005). The positive charge present on the surface of LDH due to partial substitution of trivalent ion for the divalent metal ion is another mechanism for the sorption of anionic species on the LDH.

There is no globally accepted definition for NPDs; thus, for this study, we have considered NPDs as plastic items with at least one dimension smaller than $<1 \mu \mathrm{m}$. In this study, we have used negatively charged polystyrene (PS) nanoparticles as a model for NPDs because it has been widely reported that commonly used forms of plastics, on erosion possess negative charge on their surface (Fotopoulou and Karapanagioti, 2015; Hossain et al., 2019). Nanostructured Zn-Al layered double hydroxide ( $\mathrm{Zn}-\mathrm{Al} \mathrm{LDH})$ was synthesized and used for the adsorption of NPDs from aqueous solution. The effect of coexisting anionic species and varying solution $\mathrm{pH}$ on the adsorption was also investigated. To mimic the environmental conditions, the adsorption behavior of NPDs on Zn-Al LDH in synthetic freshwater (SF) and synthetic hard water (SH) was also studied.

\section{Materials and methods}

In this study, hydrophilic polystyrene nanoparticles coated with an anionic surfactant has been used to mimic the naturally present NPDs in the environment. Because, during the abiotic degradation process of primary plastics to their secondary form, the production of carbonyl groups increases the hydrophilicity of different types of plastic polymers used in daily utilities (Gewert et al., 2015).

\subsection{Materials}

Polystyrene (PS) nanoparticles as a model of NPDs were procured from Sigma Aldrich (the indicated diameter of the particles is $55 \mathrm{~nm}$ and hydrophilic in nature as coated with an anionic surfactant to make them uniformly disperse in water). $\mathrm{ZnCl}_{2}, \mathrm{Al}\left(\mathrm{NO}_{3}\right)_{3} .9 \mathrm{H}_{2} \mathrm{O}, \mathrm{NaOH}$, $\mathrm{NaNO}_{3}, \mathrm{Na}_{2} \mathrm{SO}_{4}, \mathrm{NaHPO}_{4}, \mathrm{NaHCO}_{3}$, and $\mathrm{NaCl}$ were obtained from Merck, India.

\subsection{Synthesis of $\mathrm{Zn}-\mathrm{Al} L \mathrm{LH}$}

Zn-Al LDH were prepared by the coprecipitation method, according to Kloprogge et al. (2004), with slight modifications (Kloprogge et al., 2004; Youssef et al., 2013). Briefly, the solution containing $\mathrm{Zn}^{2+}$ $\left(0.75 \mathrm{M} \mathrm{ZnCl}_{2}\right)$ and $\mathrm{Al}^{3+}\left(0.25 \mathrm{M} \mathrm{Al}^{3}\left(\mathrm{NO}_{3}\right)_{3} .9 \mathrm{H}_{2} \mathrm{O}\right)$ was coprecipitated at constant pH 8 by using $2 \mathrm{M} \mathrm{NaOH}$. After coprecipitation, the solution was stirred vigorously for $1 \mathrm{~h}$ and kept at $70^{\circ} \mathrm{C}$ for $24 \mathrm{~h}$. After aging, the precipitate was filtered, dried at $85^{\circ} \mathrm{C}$ for $24 \mathrm{~h}$, and stored (Fig. 1). The method used for the preparation of adsorbent i.e., $\mathrm{Zn}$-Al LDH in this study, will result in the formation of the hydrophilic surface of the $\mathrm{Zn}$ Al LDH (Youssef et al., 2013).

\subsection{Characterization of the $L D H$ and NPDs}

Morphology of the LDH and NPDs was studied by using field emission scanning electron microscope (FESEM by Carl Zeiss SUPRA 55 V P FESEM) and transmission electron microscopy (TEM by JEOL, JEM $2100 \mathrm{HR}$ model). Zeta potential and $\mathrm{pH}_{\mathrm{PZC}}$ (the value of $\mathrm{pH}$ where the net charge on the surface of the particle is zero) of Zn-Al LDH and NPDs in aqueous suspension were estimated with Malvern Zetasizer (Nano ZS90) equipped with an accessory, MPT-2 multi-purpose pH titrator (Malvern).

Surface area and porosity measurements of the $\mathrm{Zn}-\mathrm{Al} \mathrm{LDH}$ and were carried out by using nitrogen as adsorbate at $77 \mathrm{~K}$ on Quantachrome Quadrasorb automatic volumetric instrument (Anton-Paar). Before the adsorption measurements, the sample was degassed at $100^{\circ} \mathrm{C}$ for $6 \mathrm{~h}$ under vacuum. The surface area was calculated by using the Brunauer Emmett-Teller (BET) method in the range of relative pressure applied between 0.05 to 0.3 for mesoporous $\mathrm{Zn}$-Al LDH. The pore size distribution was deduced by using density functional theory (DFT).

Surface area measurements of Zn-Al LDH-NPDs mixture (reaction precipitate) after sorption were also performed to get evidence about the presence of NPDs on the surface of $\mathrm{Zn}-\mathrm{Al} \mathrm{LDH}$.

The crystal phase of Zn-Al LDH was determined by powder X-ray diffraction (PXRD) using a Rigaku (mini flex II, Japan) PXRD with a high-power $\mathrm{Cu}-\mathrm{Ka}$ radioactive source (wavelength $=0.154 \mathrm{~nm}$ ) operating at $40 \mathrm{kV}$ and $70 \mathrm{~mA}$. Measurement was taken in the step scan mode from $5^{\circ}$ to $70^{\circ} 2 \theta$ range at a scanning rate of $5^{\circ} 2 \theta$ per minute.

The Fourier transform infrared (FTIR) spectra of Zn-Al LDH and NPDs were recorded in the range of $4000-400 \mathrm{~cm}^{-1}$, with 32 scans having a resolution of $4 \mathrm{~cm}^{-1}$, before and after adsorption by Thermo Scientific Nicolet iS5 FTIR spectrometer equipped with accessory attenuated total reflection (ATR).

\subsection{Sorption studies}

For the batch experiment, a stock solution of $250 \mathrm{mg} / \mathrm{L}$ NPDs was prepared in deionized (DI) water. Sorption experiments were carried out in $50 \mathrm{~mL}$ glass vials by mixing $10 \mathrm{~mL}$ of NPDs solution with $5 \mathrm{mg}$ of $\mathrm{Zn}-\mathrm{Al} \mathrm{LDH}$ and kept for shaking at $200 \mathrm{rpm}$. The reaction mixtures were centrifuged (Thermo Scientific Sorvall ST16R) at $4800 \mathrm{rpm}$ for $2 \mathrm{~min}$, and the supernatant was analyzed for residual concentration of NPDs by

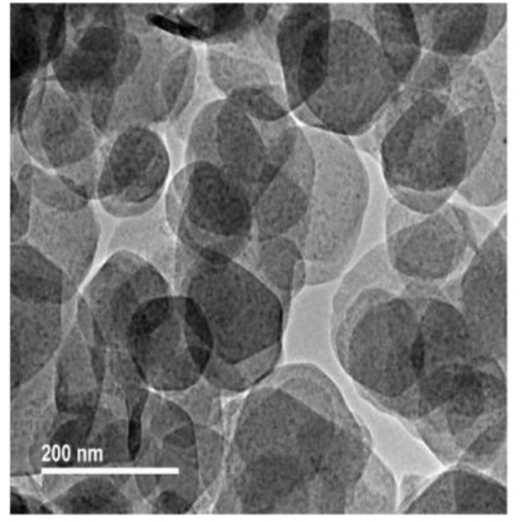

(a)

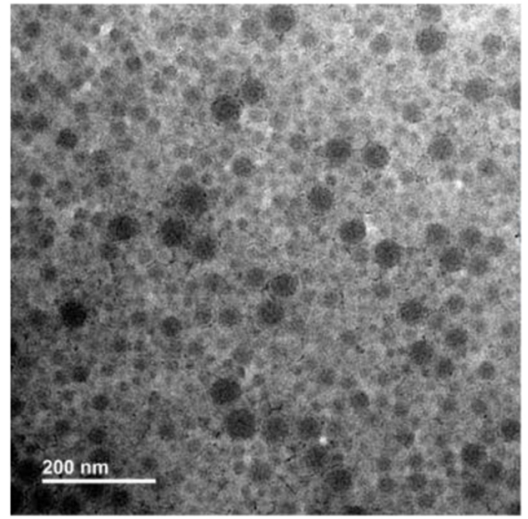

(b)

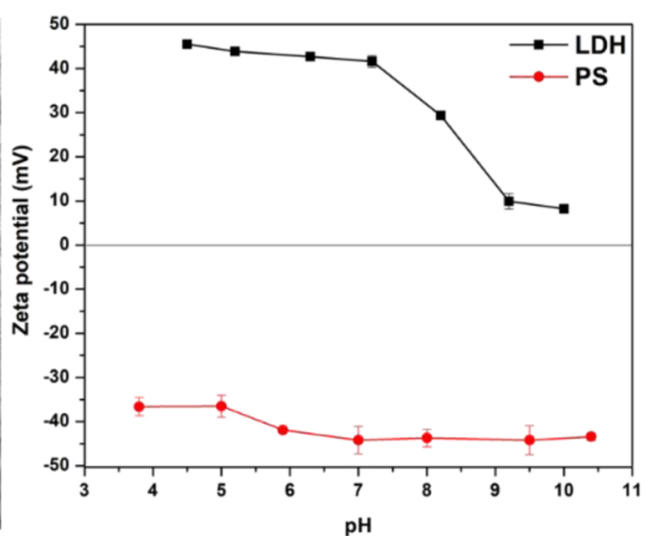

(c)

Fig. 2. TEM image of (a) LDH (b) Polystyrene (PS) nanoparticles, and (c) Zeta potential of LDH and Polystyrene nanoparticles as a function of pH. 
using a fluorescence spectrometer (JASCO FP-8300 fluorometer).

Impact of various physiochemical parameters, i.e., $\mathrm{pH}$, contact time, and competitive ions, was studied at room temperature $\left(25^{\circ} \mathrm{C}\right)$ and a fixed concentration of NPDs, while for isotherm studies NPDs concentration was varied till $70 \mathrm{mg} / \mathrm{L}$ to minimize the impact of their selfaggregation in the presence of LDH. Further, to study the thermodynamics of the sorption, both temperature and NPDs concentrations were varied by keeping the contact time constant. Solution pH 6.5 was kept constant in all the experiments except while studying the $\mathrm{pH}$ effect.

Adsorption of NPDs in the complex water system, i.e., SF and SH, was also studied, and the compositions of synthetic waters have been provided in SI Table S1.

For QA/QC of all the data, control experiments were carried out in parallel under similar conditions without the addition of $\mathrm{Zn}-\mathrm{Al} \mathrm{LDH}$.

Sorption capacity (q) of Zn-Al LDH was calculated from the following equation:

Sorption capacity $(q)=\frac{\left(C_{0}-C_{t}\right) V}{m} \mathrm{mg} / \mathrm{g}$

Where $\mathrm{C}_{0}$ and $\mathrm{C}_{\mathrm{t}}$ are initial and final concentration after time $\mathrm{t}$ of NPDs in the solution $(\mathrm{mg} / \mathrm{L}), \mathrm{q}$ is the sorption capacity of $\mathrm{Zn}-\mathrm{Al} \mathrm{LDH}(\mathrm{mg} / \mathrm{g})$, $\mathrm{V}$ is the total volume of suspension ( $\mathrm{ml}$ ), and $\mathrm{m}$ is the dry weight of the adsorbent (mg).

\section{Results and discussion}

\subsection{Characterization of the LDH and NPDs}

The surface morphology and average size of Zn-Al LDH and NPDs were estimated by TEM. (Fig. 2a) show the size of nanostructured Zn-Al LDH was less than $100 \mathrm{~nm}$ with regular hexagonal structure, and the size of the uniformly distributed spherical NPDs was approximately $50 \mathrm{~nm}$ (Fig. 2b). At pH 4 and 10, the zeta potential of $\mathrm{Zn}$-Al LDH was $45.5 \pm 0.6 \mathrm{mV}$ and $8 \pm 1 \mathrm{mV}$, respectively, while for NPDs the zeta potential ranged from $-36.8 \pm 2 \mathrm{mV}$ to $-43.4 \pm 0.9 \mathrm{mV}$ at $\mathrm{pH} 4$ and 10 respectively (Fig. 2c), indicating the particles were oppositely charged in $\mathrm{pH}$ range $4-10$, having no point of zero charge.
Surface area measurements of $\mathrm{Zn}-\mathrm{Al} \mathrm{LDH}$ at $77 \mathrm{~K}$ shows a surface area of $21.01 \mathrm{~m}^{2} / \mathrm{g}$. The pore size distribution calculated by using the DFT method indicates the presence of both micro and mesopores on the surface of $\mathrm{Zn}-\mathrm{Al} \mathrm{LDH}$. The total calculated pore volume was found to be $0.059 \mathrm{cc} / \mathrm{g}$ having an average pore diameter of $1.6 \mathrm{~nm}$ (SI fig. S2).

pXRD pattern of nanostructured Zn-Al LDH was obtained (SI fig. S4). The characteristic peaks of hydrotalcite-like LDH materials were observed; sharp peaks obtained at a small $2 \theta$ angle corresponds to diffraction by (003), (006) planes, and indicate the large interlayer spacing (Wang et al., 2008; Ookubo et al., 1992; Zhang et al., 2014). At high $2 \theta$ value, reflection from (012), (015), and (110) planes were observed, which indicates the hexagonal lattice with 3R symmetry (Zhou et al., 2011).

\subsection{LDH-NPDs interaction studies}

FTIR spectra and $\mathrm{pH}$ titration of the nanostructured $\mathrm{Zn}-\mathrm{Al} \mathrm{LDH}$ before and after sorption were performed to see the initial interaction between Zn-Al LDH with NPDs (Fig. 3). After adsorption of NPDs, the zeta potential of $\mathrm{Zn}-\mathrm{Al} \mathrm{LDH}$ decreased significantly at different $\mathrm{pH}$, and $\mathrm{pH}_{\text {PZC }}$ shifted towards lower $\mathrm{pH}$ with increasing the concentration of NPDs (Fig. 3a). Hence, pH titration confirmed the interaction between $\mathrm{Zn}-\mathrm{Al} \mathrm{LDH}$ and NPDs. FTIR analysis further confirmed the Zn-Al LDH NPDs interaction. The new bands have appeared after adsorption of NPDs on LDH at $1332 \mathrm{~cm}^{-1}$, and $697 \mathrm{~cm}^{-1}$ (Fig. 3b). These new peaks might be indicating the formation of the complex (M-O-NPDs) between NPDs and $\mathrm{Zn}-\mathrm{Al} \mathrm{LDH}$ by replacing the (M-OH) surface hydroxyl groups of LDH.

The BET measurements performed after sorption (SI fig. S3) showed an increase in surface area from $21.09 \mathrm{~m}^{2} / \mathrm{g}$ to $28.15 \mathrm{~m}^{2} / \mathrm{g}$. This increase in the surface area also indicated the presence of NPDs on the surface of LDH and confirmed the interaction between both the particles.

Further, sequential batch sorption experiments were performed to get a clear insight into the interaction mechanism and applicability of $\mathrm{Zn}-\mathrm{Al} \mathrm{LDH}$ for the removal of NPDs from aqueous system.

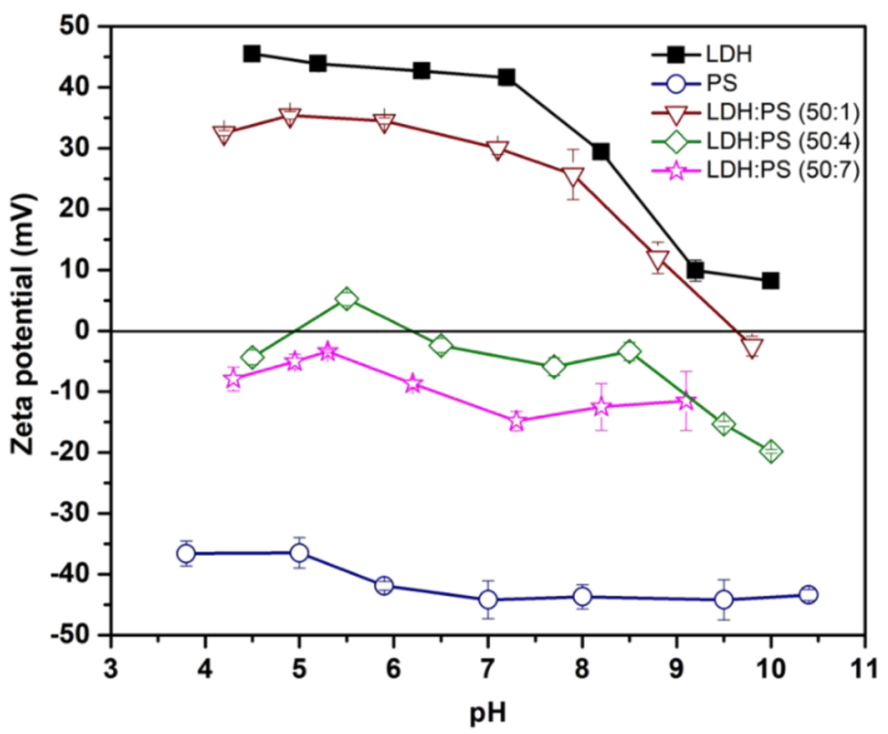

(a)

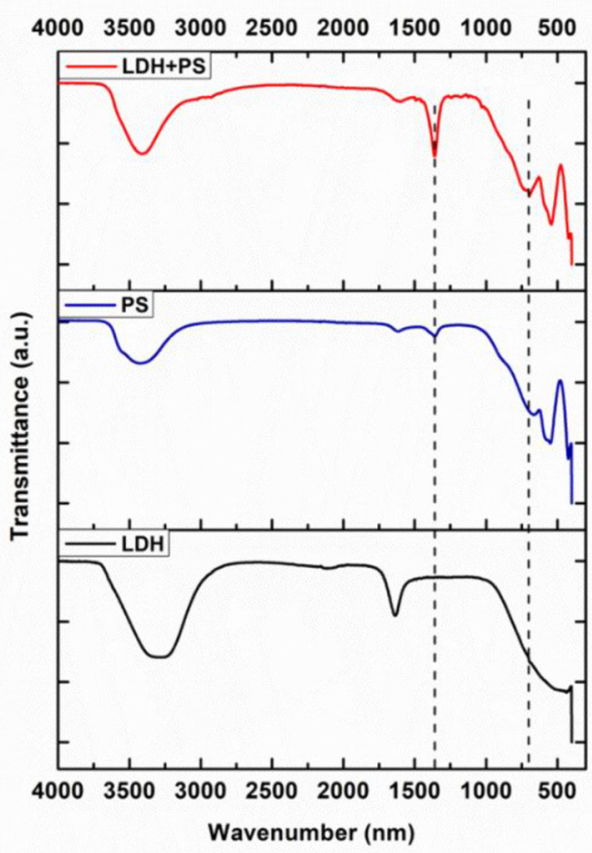

(b)

Fig. 3. (a) Zeta potential and (b) FTIR spectra of Zn-Al LDH and polystyrene (PS) NPDs mixture before and after adsorption. 


\subsection{Sorption studies}

Initially, preliminary experiments have been performed (SI Fig. S5) to obtain equilibration time for the NPDs-LDH-DI water system, i.e., $2 \mathrm{~h}$, and the same was used for all further batch experiments except during kinetic studies.

\subsubsection{Effect of environmental parameters: competitive anions and $p H$}

Ionic strength and $\mathrm{pH}$ of the solution are a significant factor which influences the adsorbent - adsorbate interaction, by inducing binding site competition and change in the functional group present at the surface of the adsorbent (Khandelwal et al., 2019). So, the effect of different concentrations of anions $\left(\mathrm{Cl}^{-}, \mathrm{HCO}_{3}{ }^{-}, \mathrm{SO}_{4}{ }^{2-}, \mathrm{PO}_{4}{ }^{3-}\right.$, and $\mathrm{NO}_{3}{ }^{-}$) and a wide range of $\mathrm{pH}$ (4-9) on adsorption was studied (Fig. 4).

As shown in Fig. 4a, a clear difference in adsorption capacity can be seen at various concentrations of competitive anions. The effect of competitive anions on sorption capacity followed sequence as: $\mathrm{Cl}^{-}<\mathrm{NO}_{3}{ }^{-}<\mathrm{HCO}_{3}{ }^{-}<\mathrm{PO}_{4}{ }^{3-}<\mathrm{SO}_{4}{ }^{2-}$. As compared to other anions, only $2 \mathrm{mM}$ concentration of $\mathrm{SO}_{4}{ }^{2-}$ and $\mathrm{PO}_{4}{ }^{3-}$ was sufficient for a significant reduction in the sorption where $2 \%$ of removal was observed (Fig. 4a). In the case of $\mathrm{HCO}_{3}$ - the reduction in adsorption capacity was observed at slightly higher concentration, i.e., $5 \mathrm{mM}$, while no significant effect was observed in the presence of $\mathrm{Cl}^{-}$and $\mathrm{NO}_{3}$ - ions. The drastic decrease in sorption capacity in the presence of $\mathrm{SO}_{4}{ }^{2-}, \mathrm{PO}_{4}{ }^{3-}$ and $\mathrm{HCO}_{3}$ - can be attributed to their specific affinity towards LDH (Wang et al., 2014; Caporale et al., 2013; Ulibarri et al., 2001).

The removal efficiency at different solution $\mathrm{pH}$ was determined by varying $\mathrm{pH}$ between 4-9, as shown in Fig. 4b. Results show NPDs sorption was highly dependent on the $\mathrm{pH}$ of the solution. The removal efficiency (RE) decreased with an increase in $\mathrm{pH}$, i.e. $100 \%$ at $\mathrm{pH} 4$ and reached $37 \%$ at $\mathrm{pH} 9$ (Fig. 4b). The effect of $\mathrm{pH}$ on the sorption of NPDs by $\mathrm{Zn}-\mathrm{Al} \mathrm{LDH}$ can be explained in terms of the point of zero charges $\left(\mathrm{pH}_{\mathrm{PZC}}\right.$ ). As shown (Fig. 2c), $\mathrm{Zn}-\mathrm{Al} \mathrm{LDH}$ had $\mathrm{pH}_{\mathrm{PZC}}$ above $\mathrm{pH} 10$ and positively charged surface in the whole $\mathrm{pH}$ range studied here. While the NPDs were highly negatively charged in the studied $\mathrm{pH}$ range. Hence the interaction was highest at $\mathrm{pH} 4$. With an increase in $\mathrm{pH}$ of the solution, the zeta potential of Zn-Al LDH decreased due to the deprotonation of surface hydroxyl groups and was near zero at $\mathrm{pH} 9$ where adsorption was least.

\subsubsection{Effect of contact time: sorption kinetics}

The rate of adsorption of NPDs on $\mathrm{Zn}-\mathrm{Al}$ LDH as a function of contact time in different types of waters has been shown in Fig. 5. In order to get the insight of adsorption mechanism, pseudo-first-order, pseudo-second-order, and general-order reaction kinetics models were

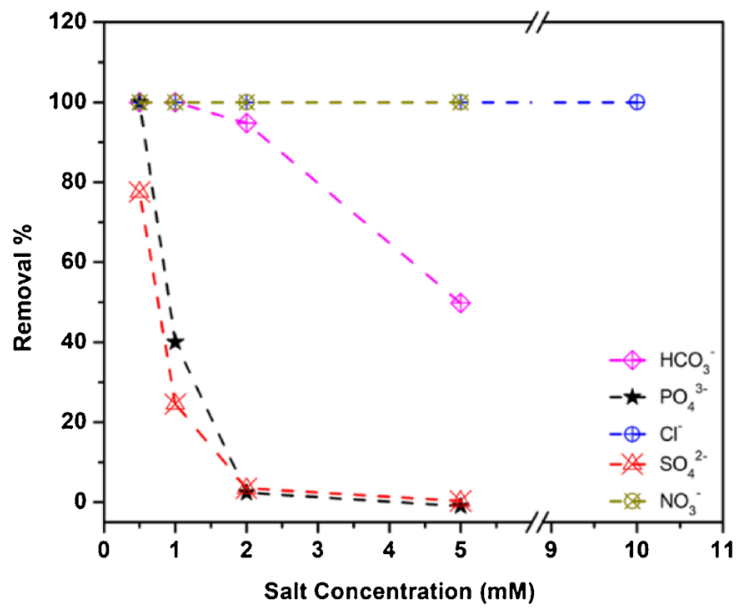

(a) used (Wamba et al., 2017). The mathematical forms of all the used kinetics models have been provided in SI (S-3). Kinetics curve and parameters have been deduced by using nonlinear fitting of the abovementioned different kinetic models. The best-fit for different kinetic models was evaluated by using the adjusted determination coefficient $\left(\mathrm{R}_{\text {adj }}^{2}\right)$ value that has been provided in Table 1 , along with all other parameters.

It is clear from the data presented in Table 1 that among all the studied models, the general-order kinetic model showed the highest $\mathrm{R}_{\text {adj }}^{2}$ values from $0.91-0.95$ for all types of water studied here. This suggests that the $\mathrm{q}_{\mathrm{t}}$ value predicted by the general-order model is the closest to experimentally measured $\mathrm{q}_{t}$ value.

The adsorption behavior of NPDs on Zn-Al LDH was varying with different water compositions. The rate of removal was fast and highest in DI and SF and slow and least in SH that can be directly correlated with the obtained rate constants and predicted $q_{t}$ values (Fig. $5 d$ ).

\subsubsection{Effect of NPDs concentration on sorption capacity in the various types of water}

To understand the impact of adsorbate concentration on the sorption capacity of adsorbent, NPDs concentration was varied by keeping LDH amount constant, i.e., $5 \mathrm{mg}$ at different temperatures (i.e., $15^{\circ} \mathrm{C}$, $25^{\circ} \mathrm{C}$ and $35^{\circ} \mathrm{C}$ ). Nanoparticles can self-aggregate at very high concentrations in the presence of LDH and therefore, at high concentrations, removal can be a combination of both sorption and aggregation.

For further insight on the sorption phenomenon, experiments were kept limited to the highest concentration of $70 \mathrm{mg} / \mathrm{L}$ of NPDs, even if the plateau was not achieved. Since the plateau was not observed, obtained data were modeled using only non-linear Freundlich and Sips isotherms to get some insights about the nature of sorption and sorption capacities. The equilibrium curves have been presented in Fig. 6, and all the parameters obtained for both isotherms were shown in Table 2.

Results in Fig. 6 show an increase in the sorption capacity with the increase of NPDs concentration in all different water types, i.e., DI, SF, and SH. Interestingly, removal in soft water was slightly higher than DI at high concentrations of NPDs while it was lowest in the case of SH. The highest removal in the case of SF can be explained by the selfaggregation of NPDs due to the presence of different ionic species in the solution. While lowest removal in the case of SH can be attributed due to competitive site binding by the high concentrations of anionic species present as described in Fig. 4a and decrease in stability of LDH at high $\mathrm{pH}$ of synthetic hard water. The decrease in the stability of LDH in $\mathrm{SH}$ can be explained by the $\mathrm{pH}$ titration curve (Fig. 2c), as the decrease in the zeta potential of $\mathrm{LDH}$ was observed above $\mathrm{pH} 8$ and was near to $\mathrm{pH}_{\mathrm{PZC}}$ value. The faster coverage of the LDH surface by DOM may be

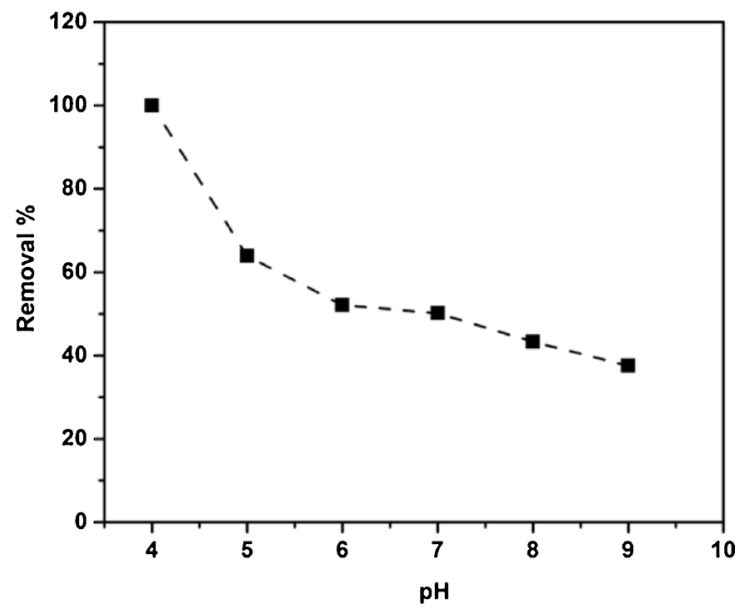

(b)

Fig. 4. Effect of (a) concentration of ions and (b) $\mathrm{pH}$ on the removal efficiency of Zn-Al LDH. 

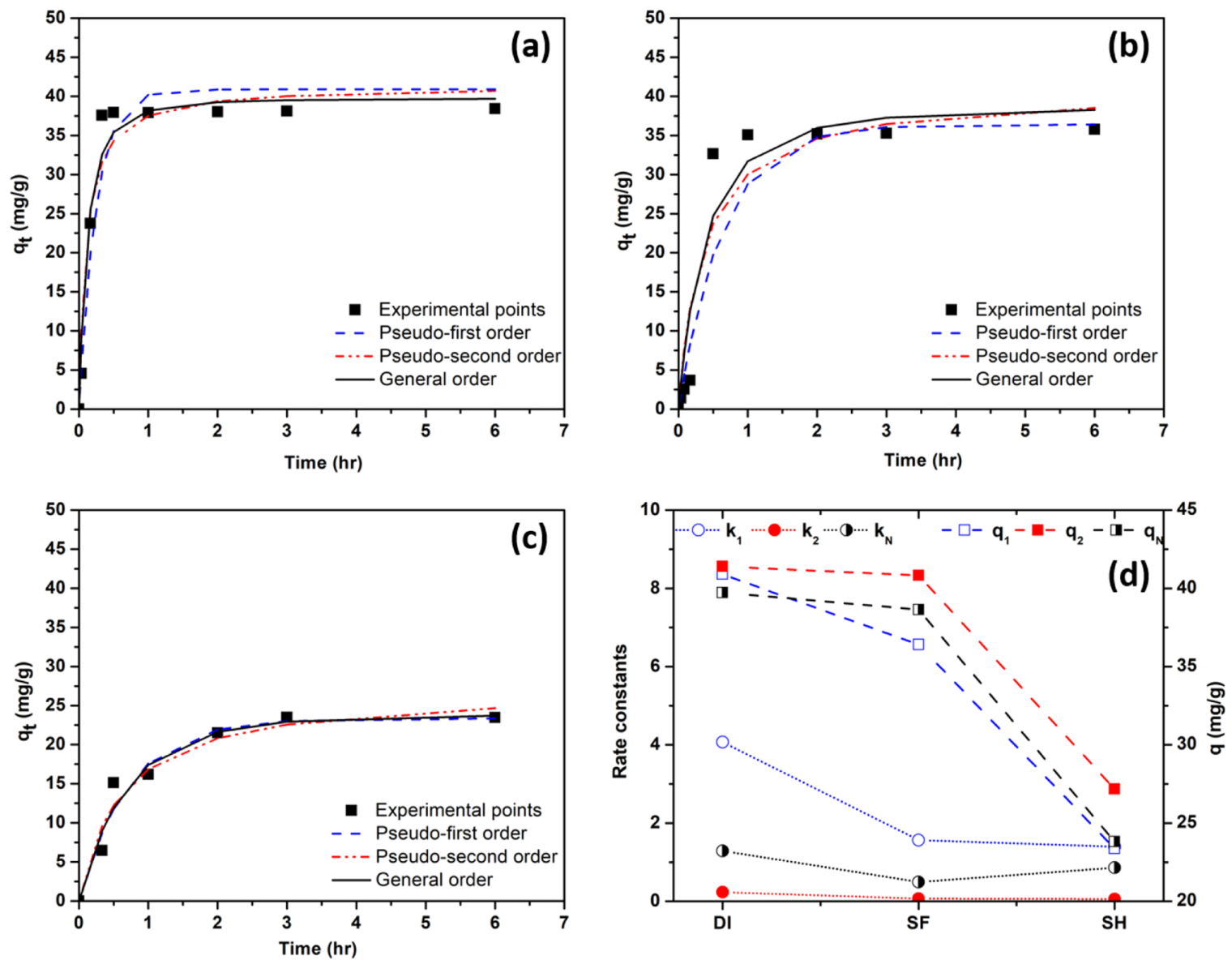

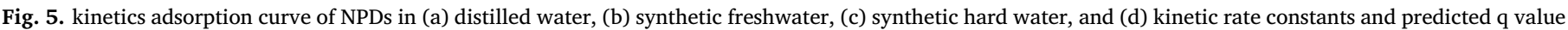
by different kinetic models in various types of water.

Table 1

Adsorption rate constant and adjusted determination coefficient for all reaction kinetics models.

\begin{tabular}{lllll}
\hline \multirow{2}{*}{ Kinetics model } & Model parameters & \multicolumn{2}{l}{ Water type } \\
\cline { 3 - 5 } \cline { 3 - 4 } & & $\mathrm{DI}$ & $\mathrm{SF}$ & $\mathrm{SH}$ \\
\hline \multirow{2}{*}{ Pseudo first order } & $\mathrm{k}_{1}\left(\mathrm{~min}^{-1}\right)$ & 4.07 & 1.56 & 1.39 \\
& $\mathrm{q}(\mathrm{mg} / \mathrm{g})$ & 40.89 & 36.4 & 23.36 \\
& $\mathrm{R}^{2}$ & 0.91 & 0.89 & 0.79 \\
Pseudo second order & $\mathrm{k}_{2}\left(\mathrm{~g} \mathrm{mg}^{-1} \mathrm{~min}^{-1}\right)$ & 0.23 & 0.068 & 0.060 \\
& $\mathrm{q}\left(\mathrm{mg} / \mathrm{g}^{2}\right.$ & 41.40 & 40.82 & 27.17 \\
General-order & $\mathrm{R}^{2}$ & 0.92 & 0.90 & 0.94 \\
& $\mathrm{k}_{\mathrm{N}}\left(\mathrm{min}^{-1}\left(\mathrm{~g} \mathrm{mg}^{-1}\right)^{\mathrm{n}-1}\right)$ & 1.28 & 0.49 & 0.85 \\
& $\mathrm{q}_{\mathrm{t}}$ & 39.73 & 38.64 & 23.8 \\
& $\mathrm{~N}$ & 1.5 & 1.45 & 1.16 \\
& $\mathrm{R}^{2}$ & 0.95 & 0.91 & 0.91 \\
\hline
\end{tabular}

another mechanism to provide stabilization through electrostatic repulsion in the system, as discussed in our previous studies (Singh et al., 2019; Tiwari et al., 2020). The order of obtained maximum sorption capacities at room temperature from the Sip isotherm model was DI $(164.4 \mathrm{mg} / \mathrm{g}) \approx \mathrm{SF}(162.6 \mathrm{mg} / \mathrm{g})>\mathrm{SH}(53.2 \mathrm{mg} / \mathrm{g})$. Good fitting with Freundlich isotherm and $n>1$ (Table 2) clearly suggests multilayer stacking with the non-ideal nature of sorption.

\subsection{Adsorption thermodynamics}

The effect of temperature on the adsorption process was also studied and isotherm curves have been presented in Fig. 6. But it is clear from the graphs that the effect of temperature on the adsorption process is minimal; therefore, we have only calculated the change in Gibbs free energy $\left(\Delta G^{0}\right)$ for the sorption process to confirm the feasibility of sorption of NPDs on $\mathrm{LDH}$. The equation used for calculating $\Delta \mathrm{G}^{0}$ values are given as following (Lima et al., 2019) :

$\Delta G^{0}=-R T \ln K_{e}^{0}$

$K_{e}^{0}=\frac{\left(K_{\mathrm{g}} . \text { molecular weight of adsorbate }\right) .[\text { adsorbate }]^{0}}{\gamma}$

Where $\mathrm{R}$ is the universal gas constant in $\mathrm{J} \mathrm{mol}^{-1} \mathrm{~K}^{-1}$, T is the temperature in $\mathrm{K}, K_{e}^{0}$ is the thermodynamic equilibrium constant, $\mathrm{K}_{\mathrm{g}}$ is the best-fitted isotherm model and $\gamma$ is the coefficient of activity. The negative value of $\Delta \mathrm{G}^{0}$ at all the studied temperatures in the case of various types of water indicates the adsorption is favourable and spontaneous in all the waters studied here. The values obtained for $\Delta G^{0}$ at all temperatures and different types of waters fall in the range of -7 to $-25 \mathrm{KJ} /$ mol (Table 3), which indicates the process of sorption is physio-sorption in nature (Humpola et al., 2013).

\subsection{Desorption, reusability of adsorbent and insight about sorption mechanism}

After performing the sorption experiments, the recovery of NPDs from LDH has also been investigated to check the reusability of LDH (Fig. 7). The reaction mixture has been acidified till $\mathrm{pH}$ less than 2 after reaching equilibrium and agitated vigorously for complete desorption of NPDs from LDH. The recovery of NPDs was observed to be $100 \%$ because of the dissolution of LDH. The solution containing NPDs, $\mathrm{Zn}^{2+}$, and $\mathrm{Al}^{3+}$ was centrifuged at $10,000 \mathrm{rpm}$ for $2 \mathrm{~min}$, and NPDs have been separated. 

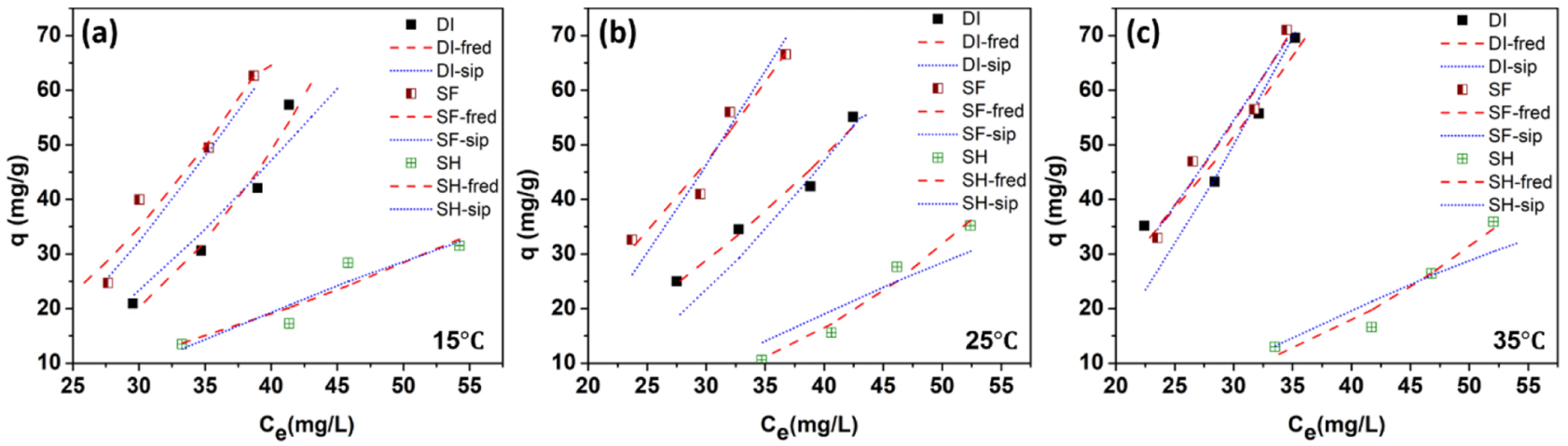

Fig. 6. Adsorption isotherm curves of NPDs at (a) $15^{\circ} \mathrm{C}$ (b) $25^{\circ} \mathrm{C}$, and (c) $35^{\circ} \mathrm{C}$ in different types of waters.

The solution containing $\mathrm{Zn}^{2+}$ and $\mathrm{Al}^{3+}$ was co-precipitated with the help of $\mathrm{NaOH}$ at $\mathrm{pH} 8$, for its further use. A small video clip showing recovery experiments performed in the laboratory has also been provided as supplementary information.

Since, both the particles used in this study i.e., adsorbent and adsorbate, are oppositely charged in nature and hence electrostatic interaction is the major phenomenon which leads to the sorption of negatively charged NPDs on the positively charged surface of $\mathrm{Zn}-\mathrm{Al} \mathrm{LDH}$. The electrostatic interaction between both the particles further causing their aggregation and removal from the aqueous solution via sedimentation (Fig. 7).

To get more insight into the interaction mechanism between NPDs and $\mathrm{Zn}-\mathrm{Al} \mathrm{LDH}, \mathrm{TEM}$, STEM, and elemental mapping were performed before and after adsorption to confirm the presence of NPDs on the surface of Zn-Al LDH. As shown in Fig. 8, more aggregated particles were observed after adsorption (Fig. 8f) due to electrostatic interaction between adsorbate and adsorbent, which is also in support of $\mathrm{pH}$ titration measurements. The presence of NPDs on the surface of $\mathrm{Zn}-\mathrm{Al}$ LDH further confirmed by elemental mapping of the adsorbent before and after sorption (Fig. 8e \& j), results showed a high concentration of carbon was present after sorption and confirmed the presence of NPDs on $\mathrm{Zn}-\mathrm{Al} \mathrm{LDH}$.

The surface properties of adsorbent were related to $\mathrm{pH}$, at lower $\mathrm{pH}$ value, the surface of $\mathrm{Zn}-\mathrm{Al} \mathrm{LDH}$ became protonated as $-\mathrm{OH}^{2+}$ group would be present on the surface. So, the negatively charged NPDs can be easily adsorbed on the surface, and the same was observed previously in section 3.2 (Fig. 3a). The shift in the $\mathrm{pH}_{\mathrm{PZC}}$ after sorption shows the specific adsorption of NPDs on Zn-Al LDH rather than a simply electrostatic attraction.

Moreover, the interaction between NPDs and LDH has also been confirmed by surface area measurements after sorption (SI fig. S3). Since polystyrene particles were of $55 \mathrm{~nm}$ in size, so they also have their own surface area. Therefore, the adsorption of NPDs on LDH had shown an overall increase in the total surface area of reaction precipitate after sorption.

Also, the values obtained for Gibbs free energy suggests the adsorption of NPDs on LDH is favorable and spontaneous in nature. The process of sorption is more likely to be physical sorption. This might also be supported by the $100 \%$ recovery of NPDs, which shows the
Table 3

Gibbs free energy value for NPDs sorption on nanostructured $\mathrm{Zn}$-Al LDH in different types of waters at different temperatures.

\begin{tabular}{llll}
\hline \multirow{2}{*}{ Water } & $\Delta \mathrm{G}^{0}\left(\mathrm{~kJ} \mathrm{~mol}^{-1}\right)$ & & \\
\cline { 2 - 4 } & $288 \mathrm{~K}$ & $298 \mathrm{~K}$ & $308 \mathrm{~K}$ \\
\hline DI & -8.07 & -20.34 & -24.10 \\
SF & -15.80 & -21.81 & -22.82 \\
SH & -17.41 & -7.27 & -11.52 \\
\hline
\end{tabular}

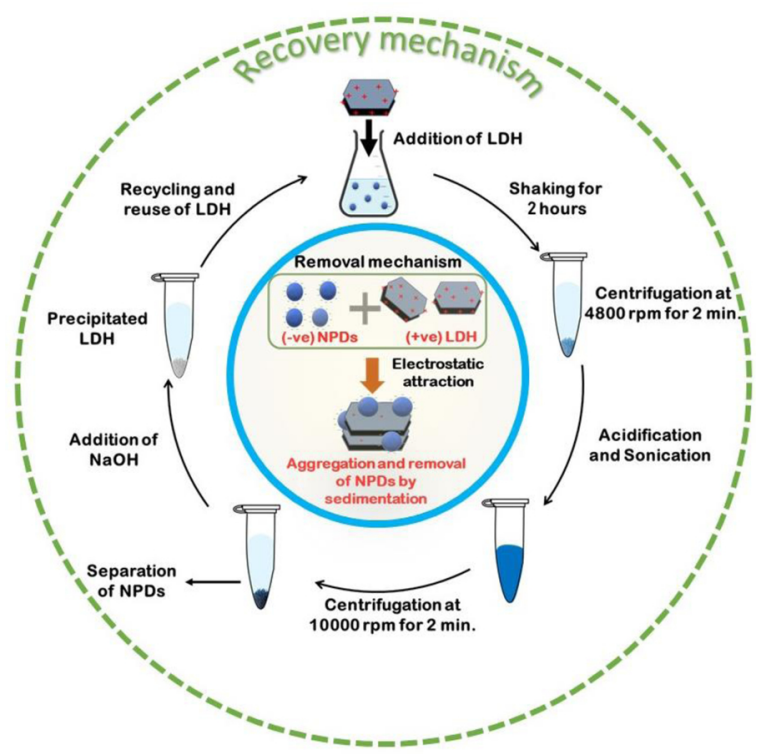

Fig. 7. Removal and recovery mechanism of nano-scale plastic debris (NPDs) from aqeous systems by using layered double hydroxides(LDH).

particles were not chemically bounded to the LDH and attached by the only weak electrostatic force of attraction, therefore complete recovery was there.

Table 2

Adsorption isotherms constants and correlation coefficient for Freundlich and Sips isotherm in different waters at $25^{\circ} \mathrm{C}$.

\begin{tabular}{|c|c|c|c|c|c|c|c|}
\hline \multirow[t]{2}{*}{ Water type } & \multicolumn{3}{|c|}{ Freundlich isotherm model } & \multirow[b]{2}{*}{$\mathrm{K}_{\mathrm{S}}\left(\mathrm{mg} \mathrm{L}^{-1}\right)^{-1 / n}$} & \multicolumn{3}{|c|}{ Sips isotherm model } \\
\hline & $\mathrm{K}_{\mathrm{F}}$ & $\mathrm{n}$ & $\mathrm{R}^{2}$ & & $\begin{array}{l}\mathrm{Q}_{\max } \\
\left(\mathrm{mg} \mathrm{g}^{-1}\right)\end{array}$ & $\mathrm{n}$ & $\mathrm{R}^{2}$ \\
\hline DI & 0.060 & 1.78 & 0.97 & $4.4 \times 10^{-6}$ & 164.49 & 3.09 & 0.96 \\
\hline SF & 0.12 & 1.75 & 0.94 & $1.05 \times 10^{-5}$ & 162.62 & 3.10 & 0.94 \\
\hline $\mathrm{SH}$ & $3 \times 10^{-4}$ & 2.92 & 0.97 & $3.14 \times 10^{-6}$ & 53.27 & 3.27 & 0.97 \\
\hline
\end{tabular}



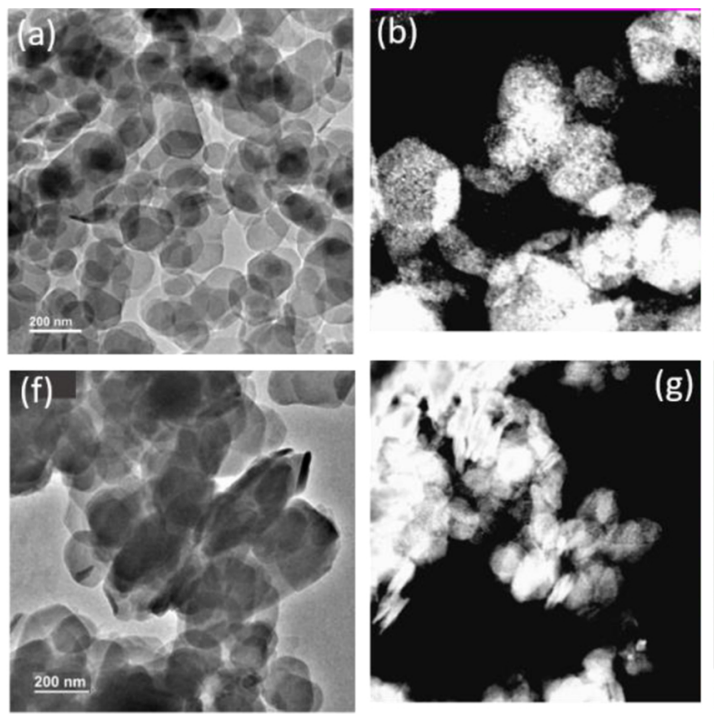

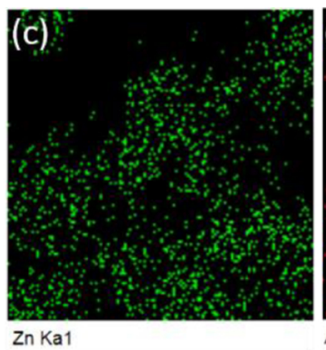

$\mathrm{ZnKa1}$

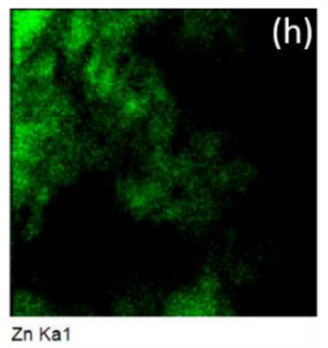

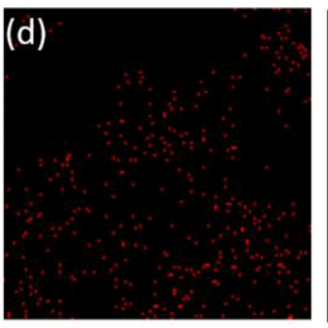

Al Ka1

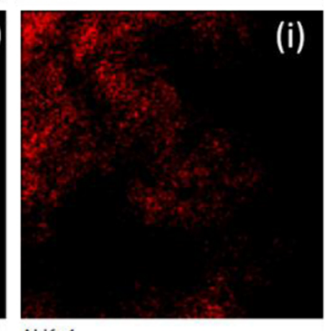

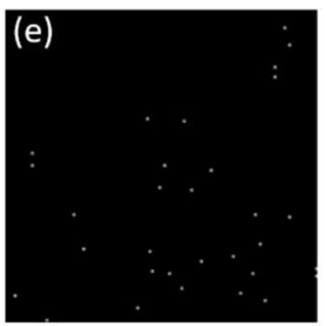

CKa1_2

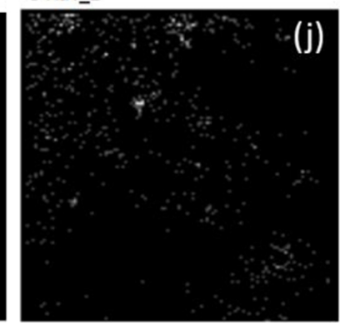

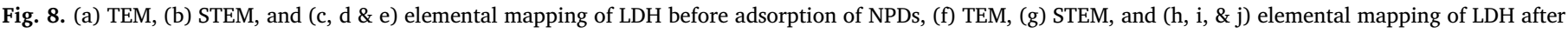
adsorption of NPDs.

\section{Conclusion}

The present study has first time reported the removal of NPDs from aqueous environment by using eco-friendly sorption techniques. Nanostructured Zn-Al LDH, which has been successfully synthesized by the co-precipitation method, was considered as a potential adsorbent for the removal of NPDs from the aqueous environment. The negatively charged NPDs were adsorbed on Zn-Al LDH by electrostatic interaction, and $96 \%$ removal of NPDs was observed in the case of DI. The coexisting anionic species and $\mathrm{pH}$ of the system influenced the adsorption of NPDs on Zn-Al LDH. Reduction in the adsorption capacity in the presence of anionic species resulted due to increased competitive binding. The removal was highest at low $\mathrm{pH}$ and decreased with an increase in the $\mathrm{pH}$ of the system. The adsorption kinetics of NPDs on ZnAl LDH in different types of waters were well described by the generalorder kinetic model. It is noteworthy; the rate of sorption was faster and higher in DI and SF, and slow and lower in SH. This can be explained by the higher aggregation of NPDs in SF due to the presence of a low concentration of different ionic species in the aqueous system. The low removal in the case of hard water can be attributed due to an increase in competitive binding sites on the surface and a decrease in the stability of adsorbent. Sips isotherm suggests $\mathrm{Zn}$-Al LDH has a very high sorption capacity for NPDs with a maximum of $164.49 \mathrm{mg} / \mathrm{g}, 162.62 \mathrm{mg} / \mathrm{g}$ and $53.27 \mathrm{mg} / \mathrm{g}$ in DI, SF, and SH respectively. Besides, equilibrium adsorption isotherms fit well with Freundlich's model in different water types of aqueous matrices with a value of $n>1$ supporting heterogeneous nature of sorption of NPDs on LDH. The thermodynamic data revealed the process of sorption was favourable and spontaneous in all types of studied water composition, but removal was least in the case of synthetic hard water. The process of sorption was more likely to be physical sorption. This might also be supported by the $100 \%$ recovery of NPDs, which shows the particles were not chemically bounded to the LDH and attached by the only weak electrostatic force of attraction, therefore complete recovery was there. However, Zn-Al LDH can be used for the removal of NPDs from the freshwater system, having a low concentration of ionic species. Further modification in the adsorbent can be explored for the good removal capacity in different types of waters.

\section{CRediT authorship contribution statement}

Ekta Tiwari: Investigation, Data curation, Conceptualization,
Writing - original draft, Writing - review \& editing. Nisha Singh: Methodology, Writing - review \& editing. Nitin Khandelwal: Conceptualization, Formal analysis, Writing - review \& editing. Fazel Abdolahpur Monikh: Conceptualization. Gopala Krishna Darbha: Supervision, Project administration, Funding acquisition, Conceptualization.

\section{Declaration of Competing Interest}

The authors declare that they have no known competing financial interests or personal relationships that could have appeared to influence the work reported in this paper.

\section{Acknowledgments}

This research is funded by the Science and Engineering Research Board (SERB), India - Ramanujan Fellowship grant (SB/S2/RJN-006/ 2016) and ECR project grant (ECR/2017/000707). We want to acknowledge the Indian Institute of Science Education and Research Kolkata's central instrumentation facility for sample analysis (FESEM and TEM) and Central instrument facility at the Department of Chemical Sciences for using the fluorescence spectrometer.

\section{Appendix A. Supplementary data}

Supplementary material related to this article can be found, in the online version, at doi:https://doi.org/10.1016/j.jhazmat.2020.122769.

\section{References}

Alimi, O.S., Farner Budarz, J., Hernandez, L.M., Tufenkji, N., 2018. Microplastics and Nanoplastics in Aquatic Environments: Aggregation, Deposition, and Enhanced Contaminant Transport. Environ. Sci. Technol. 52, 1704-1724.

Arossa, S., Martin, C., Rossbach, S., Duarte, C.M., 2019. Microplastic removal by Red Sea giant clam (Tridacna maxima). Environ. Pollut. 252, 1257-1266.

Besseling, E., Wang, B., Lürling, M., Koelmans, A.A., 2014. Nanoplastic affects growth of S. Obliquus and reproduction of D. Magna. Environ. Sci. Technol. 48, 12336-12343. Bhattacharya, P., Lin, S., Turner, J.P., Ke, P.C., 2010. Physical adsorption of charged plastic nanoparticles affects algal photosynthesis. J. Phys. Chem. C 114, 16556-16561.

Booth, A., Hansen, B., Frenzel, M., Johnsen, H., Altin, D., 2016. Uptake and toxicity of methylmethacrylate-based nanoplastic particles in aquatic organisms: ecotoxicity and uptake of nanoplastic particles. Environ. Toxicol. Chem. 35, 1641-1649.

Caporale, A.G., Pigna, M., Azam, S.M.G.G., Sommella, A., Rao, M.A., Violante, A., 2013. Effect of competing ligands on the sorption/desorption of arsenite on/from $\mathrm{Mg}$-Fe layered double hydroxides (Mg-Fe-LDH). Chem. Eng. J. 225, 704-709. 
Cardoso, L.P., Valim, J.B., 2006. Study of acids herbicides removal by calcined $\mathrm{Mg}$-Al—CO3—LDH. J. Phys. Chem. Solids 67, 987-993.

Cedervall, T., Hansson, L.-A., Lard, M., Frohm, B., Linse, S., 2012. Food chain transport of nanoparticles affects behaviour and fat metabolism in fish. PLoS One 7, e32254.

Chaara, D., Bruna, F., Ulibarri, M.A., Draoui, K., Barriga, C., Pavlovic, I., 2011. Organo/ layered double hydroxide nanohybrids used to remove non ionic pesticides. J. Hazard. Mater. 196, 350-359.

Chae, Y., Kim, D., Kim, S.W., An, Y.-J., 2018. Trophic transfer and individual impact of nano-sized polystyrene in a four-species freshwater food chain. Sci. Rep. 8, 284.

Darbha, G.K., Fischer, C., Luetzenkirchen, J., Schäfer, T., 2012. Site-specific retention of colloids at rough rock surfaces. Environ. Sci. Technol. 46, 9378-9387.

Fotopoulou, K.N., Karapanagioti, H.K., 2015. Surface properties of beached plastics, Environ. Sci. Pollut. Res. - Int. 22, 11022-11032.

Gewert, B., Plassmann, M.M., MacLeod, M., 2015. Pathways for degradation of plastic polymers floating in the marine environment. Environ. Sci. Process. Impacts 17, 1513-1521.

Gopinath, P.M., Saranya, V., Vijayakumar, S., Mythili Meera, M., Ruprekha, S., Kunal, R., Pranay, A., Thomas, J., Mukherjee, A., Chandrasekaran, N., 2019. Assessment on interactive prospectives of nanoplastics with plasma proteins and the toxicological impacts of virgin, coronated and environmentally released-nanoplastics. Sci. Rep. 9, 8860.

Hernandez, L.M., Yousefi, N., Tufenkji, N., 2017. Are There Nanoplastics in Your Personal Care Products? Environ. Sci. Technol. Lett. 4, 280-285.

Hossain, M.R., Jiang, M., Wei, Q., Leff, L.G., 2019. Microplastic surface properties affect bacterial colonization in freshwater. J. Basic Microbiol. 59, 54-61.

Humpola, P.D., Odetti, H.S., Fertitta, A.E., Vicente, J.L., 2013. Thermodynamic analysis of adsorption models of phenol in liquid phase on different activated carbons. J Chil Chem Soc 58, 1541-1544.

Jeong, C.-B., Kang, H.-M., Lee, Y.H., Kim, M.-S., Lee, J.-S., Seo, J.S., Wang, M., Lee, J.-S., 2018. Nanoplastic ingestion enhances toxicity of persistent organic pollutants (POPs) in the monogonont rotifer Brachionus koreanus via multixenobiotic resistance (MXR) disruption. Environ. Sci. Technol. 52, 11411-11418.

Khandelwal, N., Singh, N., Tiwari, E., Darbha, G.K., 2019. Novel synthesis of a clay supported amorphous aluminum nanocomposite and its application in removal of hexavalent chromium from aqueous solutions. RSC Adv. 9, 11160-11169.

Kloprogge, J.T., Hickey, L., Frost, R.L., 2004. The effects of synthesis pH and hydrothermal treatment on the formation of zinc aluminum hydrotalcites. J. Solid State Chem. 177, 4047-4057.

Koelmans, A.A., Besseling, E., Shim, W.J., 2015. Nanoplastics in the aquatic environment. Critical review. In: Bergmann, M., Gutow, L., Klages, M. (Eds.), Marine Anthropogenic Litter. Springer International Publishing, Cham, pp. 325-340.

Lares, M., Ncibi, M.C., Sillanpää, M., Sillanpää, M., 2018. Occurrence, identification and removal of microplastic particles and fibers in conventional activated sludge process and advanced MBR technology. Water Res. 133, 236-246.

Lazaridis, N.K., Pandi, T.A., Matis, K.A., 2004. Chromium(VI) removal from aqueous solutions by $\mathrm{Mg}-\mathrm{Al}-\mathrm{CO} 3$ hydrotalcite: sorption - Desorption kinetic and equilibrium studies. Ind. Eng. Chem. Res. 43, 2209-2215.

Lee, W.S., Cho, H.-J., Kim, E., Huh, Y.H., Kim, H.-J., Kim, B., Kang, T., Lee, J.-S., Jeong, J., 2019. Bioaccumulation of polystyrene nanoplastics and their effect on the toxicity of Au ions in zebrafish embryos. Nanoscale 11, 3173-3185.

Legrouri, A., Lakraimi, M., Barroug, A., De Roy, A., Besse, J.P., 2005. Removal of the herbicide 2,4-dichlorophenoxyacetate from water to zinc-aluminium-chloride layered double hydroxides. Water Res. 39, 3441-3448.

Lehner, R., Weder, C., Petri-Fink, A., Rothen-Rutishauser, B., 2019. Emergence of nanoplastic in the environment and possible impact on human health. Environ. Sci. Technol. 53, 1748-1765.

Li, J., Fan, Q., Wu, Y., Wang, X., Chen, C., Tang, Z., Wang, X., 2016. Magnetic polydopamine decorated with Mg-Al LDH nanoflakes as a novel bio-based adsorbent for simultaneous removal of potentially toxic metals and anionic dyes. J. Mater. Chem. A 4, 1737-1746.

Lima, E.C., Hosseini-Bandegharaei, A., Moreno-Piraján, J.C., Anastopoulos, I., 2019. A critical review of the estimation of the thermodynamic parameters on adsorption equilibria. Wrong use of equilibrium constant in the Van't Hoof equation for calculation of thermodynamic parameters of adsorption. J. Mol. Liq. 273, 425-434.

Liu, Y., Hu, Y., Yang, C., Chen, C., Huang, W., Dang, Z., 2019. Aggregation kinetics of UV irradiated nanoplastics in aquatic environments. Water Res. 163, 114870.

Long, Z.X., Pan, Z., Wang, W.L., Ren, J.Y., Yu, X.G., Lin, L.Y., Lin, H., Chen, H.Z., Jin, X.L., 2019. Microplastic abundance, characteristics, and removal in wastewater treatment plants in a coastal city of China. Water Res. 155, 255-265.

Ma, Y., Huang, A., Cao, S., Sun, F., Wang, L., Guo, H., Ji, R., 2016. Effects of nanoplastics and microplastics on toxicity, bioaccumulation, and environmental fate of phenanthrene in fresh water. Environ Pollut 219, 166-173.

Ma, B.W., Xue, W.J., Hu, C.Z., Liu, H.J., Qu, J.H., Li, L.L., 2019. Characteristics of microplastic removal via coagulation and ultrafiltration during drinking water treatment. Chem. Eng. J. 359, 159-167.

Mason, S.A., Garneau, D., Sutton, R., Chu, Y., Ehmann, K., Barnes, J., Fink, P., Papazissimos, D., Rogers, D.L., 2016. Microplastic pollution is widely detected in US municipal wastewater treatment plant effluent. Environ Pollut 218, 1045-1054.

Mattsson, K., Ekvall, M.T., Hansson, L.-A., Linse, S., Malmendal, A., Cedervall, T., 2015. Altered Behavior, Physiology, and Metabolism in Fish Exposed to Polystyrene Nanoparticles. Environ. Sci. Technol. 49, 553-561.

Nasser, F., Lynch, I., 2016. Secreted protein eco-corona mediates uptake and impacts of polystyrene nanoparticles on Daphnia magna. J. Proteomics 137, 45-51.

Nguyen, B., Claveau-Mallet, D., Hernandez, L.M., Xu, E.G., Farner, J.M., Tufenkji, N., 2019. Separation and analysis of microplastics and nanoplastics in complex environmental samples. Acc. Chem. Res. 52, 858-866.

Nolte, T.M., Hartmann, N.B., Kleijn, J.M., Garnæs, J., van de Meent, D., Jan Hendriks, A., Baun, A., 2017. The toxicity of plastic nanoparticles to green algae as influenced by surface modification, medium hardness and cellular adsorption. Aquat. Toxicol. 183, 11-20.

Ookubo, A., Ooi, K., Hayashi, H., 1992. Hydrotalcites as potential adsorbents of intestinal phosphate. J. Pharm. Sci. 81, 1139-1140.

Pitt, J.A., Kozal, J.S., Jayasundara, N., Massarsky, A., Trevisan, R., Geitner, N., Wiesner, M., Levin, E.D., Di Giulio, R.T., 2018. Uptake, tissue distribution, and toxicity of polystyrene nanoparticles in developing zebrafish (Danio rerio). Aquat. Toxicol. 194, 185-194.

Revel, M., Châtel, A., Mouneyrac, C., 2018. Micro(nano)plastics: a threat to human health? Curr. Opin. Environ. Sci. Health 1, 17-23.

Rothen-Rutishauser, B., Mühlfeld, C., Blank, F., Musso, C., Gehr, P., 2007. Translocation of particles and inflammatory responses after exposure to fine particles and nanoparticles in an epithelial airway model. Part. Fibre Toxicol. 4 9-9.

Singh, N., Tiwari, E., Khandelwal, N., Darbha, G.K., 2019. Understanding the stability of nanoplastics in aqueous environments: effect of ionic strength, temperature, dissolved organic matter, clay, and heavy metals. Environ. Sci. Nano 6, 2968-2976.

Tallec, K., Blard, O., González-Fernández, C., Brotons, G., Berchel, M., Soudant, P., Huvet, A., Paul-Pont, I., 2019. Surface functionalization determines behavior of nanoplastic solutions in model aquatic environments. Chemosphere 225, 639-646.

Talvitie, J., Mikola, A., Koistinen, A., Setälä, O., 2017. Solutions to microplastic pollution - removal of microplastics from wastewater effluent with advanced wastewater treatment technologies. Water Res. 123, 401-407.

Tiwari, E., Mondal, M., Singh, N., Khandelwal, N., Monikh, F.A., Darbha, G.K., 2020 Effect of the irrigation water type and other environmental parameters on $\mathrm{CeO} 2$ nanopesticide-clay colloid interactions. Environ. Sci. Process. Impacts 22, 84-94.

Ulibarri, M.A., Pavlovic, I., Barriga, C., Hermosín, M.C., Cornejo, J., 2001. Adsorption of anionic species on hydrotalcite-like compounds: effect of interlayer anion and crystallinity. Appl. Clay Sci. 18, 17-27.

Wamba, A.G.N., Lima, E.C., Ndi, S.K., Thue, P.S., Kayem, J.G., Rodembusch, F.S., dos Reis, G.S., de Alencar, W.S., 2017. Synthesis of grafted natural pozzolan with 3aminopropyltriethoxysilane: preparation, characterization, and application for removal of Brilliant Green 1 and Reactive Black 5 from aqueous solutions. Environ. Sci. Pollut. Res. 24, 21807-21820.

Wang, Y., Zhang, F., Xu, S., Wang, X., Evans, D.G., Duan, X., 2008. Preparation of layered double hydroxide microspheres by spray drying. Ind. Eng. Chem. Res. 47, 5746-5750.

Wang, W., Zhou, J., Achari, G., Yu, J., Cai, W., 2014. Cr(VI) removal from aqueous solutions by hydrothermal synthetic layered double hydroxides: adsorption performance, coexisting anions and regeneration studies. Colloids Surf. A Physicochem. Eng. Asp. 457, 33-40.

Wegner, A., Besseling, E., Foekema, E.M., Kamermans, P., Koelmans, A.A., 2012. Effects of nanopolystyrene on the feeding behavior of the blue mussel (Mytilus edulis L.). Environ. Toxicol. Chem. 31, 2490-2497.

Youssef, A.M., Bujdosó, T., Hornok, V., Papp, S., 2013. A. El Fotouh Abdel Hakim, I. Dékány, Structural and thermal properties of polystyrene nanocomposites containing hydrophilic and hydrophobic layered double hydroxides. Appl. Clay Sci. 77-78, 46-51.

Yu, F., Yang, C., Zhu, Z., Bai, X., Ma, J., 2019a. Adsorption behavior of organic pollutants and metals on micro/nanoplastics in the aquatic environment. Sci. Total Environ. 694, 133643.

Yu, S., Shen, M., Li, S., Fu, Y., Zhang, D., Liu, H., Liu, J., 2019b. Aggregation kinetics of different surface-modified polystyrene nanoparticles in monovalent and divalent electrolytes. Environ Pollut 255, 113302.

Zhang, H., Kuo, Y.-Y., Gerecke, A.C., Wang, J., 2012. Co-release of hexabromocyclododecane (HBCD) and Nano- and microparticles from thermal cutting of polystyrene foams. Environ. Sci. Technol. 46, 10990-10996.

Zhang, X.-Q., Zeng, M.-G., Li, S.-P., Li, X.-D., 2014. Methotrexate intercalated layered double hydroxides with different particle sizes: structural study and controlled release properties. Colloids Surf. B Biointerfaces 117, 98-106.

Zhang, Q., Qu, Q., Lu, T., Ke, M., Zhu, Y., Zhang, M., Zhang, Z., Du, B., Pan, X., Sun, L., Qian, H., 2018. The combined toxicity effect of nanoplastics and glyphosate on Microcystis aeruginosa growth. Environ Pollut 243, 1106-1112.

Zhou, J., Yang, S., Yu, J., Shu, Z., 2011. Novel hollow microspheres of hierarchical zinc-aluminum layered double hydroxides and their enhanced adsorption capacity for phosphate in water. J. Hazard. Mater. 192, 1114-1121. 